\title{
A Dynamic Kinetic Asymmetric Heck Reaction for the Simultaneous Generation of Central and Axial Chirality
}

\author{
José Alberto Carmona, ${ }^{\S}$ Valentín Hornillos, ${ }^{*, \$,}$ Pedro Ramírez-López, ${ }^{\S}$ Abel Ros, ${ }^{\S, f}$ Javier Iglesias-Sigüenza, ${ }^{\varsigma}$ En- \\ rique Gómez-Bengoa, Rosario Fernández, ${ }^{*, 5}$ José M. Lassaletta ${ }^{*, \$}$ \\ ${ }^{\S}$ Instituto de Investigaciones Químicas (CSIC-US) and Centro de Innovación en Química Avanzada (ORFEO-CINQA), Avda. Amé- \\ rico Vespucio, 49, 41092 Sevilla, Spain. \\ ${ }^{\text {j}}$ Departamento de Química Orgánica, Universidad de Sevilla and Centro de Innovación en Química Avanzada (ORFEO-CINQA), \\ C/ Prof. García González, 1, 41012 Sevilla, Spain. \\ • Departamento de Química Orgánica I, Universidad del País Vasco, UPV/EHU, Apdo. 1072, 20080 San Sebastián, Spain
}

\begin{abstract}
A highly diastereo- and enantioselective, scalable Pd-catalyzed dynamic kinetic asymmetric Heck reaction of heterobiaryl sulfonates with electron-rich olefins is described. The coupling of 2,3-dihydrofuran or N-boc protected 2,3-dihydropyrrole with a variety of quinoline, quinazoline, phthalazine and picoline derivatives takes place with simultaneous installation of central and axial chirality, reaching excellent diastereo- and enantiomeric excesses when in situ formed [ $\mathrm{Pd}^{0} / \mathrm{DM}-\mathrm{BINAP}$ ] was used as the catalyst, with loadings reduced down to 2 mol\% in large scale reactions. The coupling of acyclic, electron-rich alkenes can also be performed using a $\left[\mathrm{Pd}^{0} / \mathrm{Josiphos}\right.$ ligand] to obtain axially chiral heterobiaryl $\alpha$-substituted alkenes in high yields and enantioselectivities. Products from Boc-protected 2,3-dihydropyrrole can be easily transformed into $N, N$ ligands or appealing axially chiral, bifunctional proline-type organocatalysts. Computational studies suggest that a $\beta$ hydride elimination is the stereocontrolling step, in agreement with the observed stereochemical outcome of the reaction.
\end{abstract}

\section{INTRODUCTION}

The Heck reaction is a fundamental palladium-catalyzed $\mathrm{C}-\mathrm{C}$ bond-forming transformation with numerous applications in the synthesis of natural products and valuable synthetic intermediates. ${ }^{1}$ Since the first intermolecular asymmetric version reported in 1991 by the group of Hayashi, ${ }^{2}$ these couplings have become a benchmark to validate the design of novel chiral ligands and catalysts rather than finding suitable applications in stereoselective organic synthesis. ${ }^{3}$ Only very recently, the synthetic utility of the asymmetric Heck reaction has been expanded thanks to the outstanding performance of chiral mixed phosphine/phosphine oxide ligands in several representative transformations. ${ }^{4}$ Additionally, methods to enable the use of benzylic electrophiles ${ }^{5}$ and previously elusive aryl halides ${ }^{6}$ have also appeared. Moreover, conditions for the highly enantioselective construction of quaternary stereocenters from trisubstituted dihydrofurans have also been reported $^{7}$ (Scheme 1A). The redox relay Heck-Matsuda reactions of acyclic alkenyl alcohols ${ }^{8}$ have also significantly expanded the synthetic value of the reaction, a strategy that has been also extended to oxidative Heck reactions using boronic acids as reactants (Scheme 1B) ${ }^{9,10}$ Mention is also due to the dynamic kinetic resolution of atropoisomeric $o$-iodoacrylanilides. $^{11}$
Scheme 1. Asymmetric intermolecular Heck reactions.

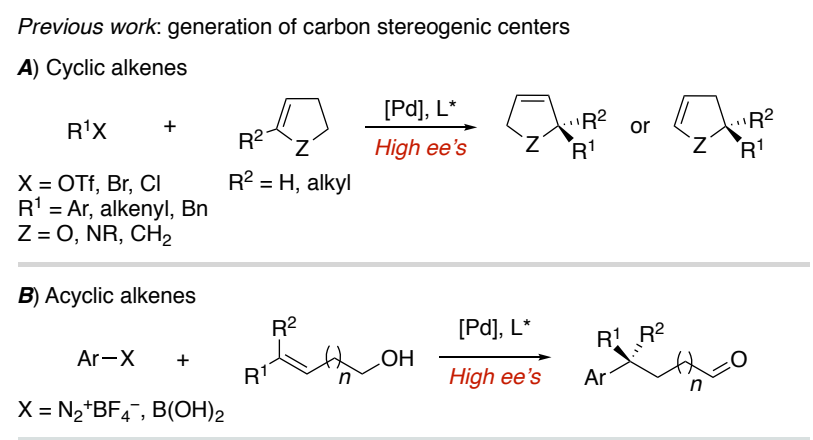

\section{This work:}

C) Dynamic kinetic asymmetric Heck Reaction

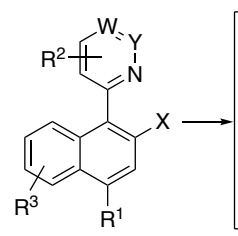

$( \pm)-1: X=O T f, O N f$ $\mathrm{W}, \mathrm{Y}=\mathrm{CH}, \mathrm{N}$

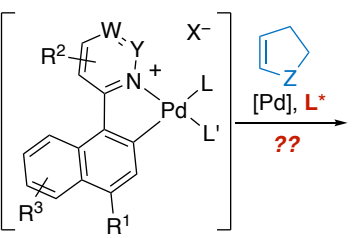

ןA

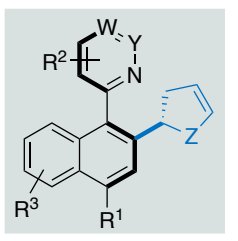

$\mathrm{Z}=\mathrm{O}, \mathrm{NBoc}$

Stereogenic axis \& center generated at once
The direct asymmetric cross-coupling approach ${ }^{12}$ to axially chiral biaryls has failed so far for the synthesis of heterobiaryls such as QUINAP and related derivatives. Among a handful of 
alternative approaches, ${ }^{13}$ our group has recently described $\mathrm{Pd}$ catalyzed dynamic kinetic asymmetric $\mathrm{C}-\mathrm{C}, \mathrm{C}-\mathrm{P}$ and $\mathrm{C}-\mathrm{N}$ cross-coupling reactions of racemic heterobiaryl sulfonates $1 .{ }^{14}$ On the other hand, more complex ligands/catalysts combining central and axial chirality have found a number of recent applications in asymmetric catalysis, ${ }^{15}$ but their synthesis usually require tedious multi-step procedures. In fact, examples of catalytic procedures for the simultaneous generation of axial and central chirality are rare, ${ }^{16}$ and none of them were directed to the synthesis of catalysts/ligands with practical applications. In this context, the dynamic kinetic asymmetric Heck reaction from $\mathbf{1}$ appears as an appealing strategy for the synthesis of bifunctional heterobiaryls with central and axial stereogenic elements (Scheme 1C). This transformation, however, is particularly challenging for two main reasons: First, in contrast with the common cationic Heck reaction pathway, ${ }^{17}$ the oxidative addition intermediate $\mathbf{I}^{\mathbf{O A}}$ has no vacant coordination sites; the relatively good isoquinoline/pyridine $\mathrm{N}$ ligand must be displaced by a neutral olefin on the $\mathrm{Pd}^{\mathrm{II}}$ center. Second, the reaction with internal olefins can afford up to 8 different Heck stereoisomers considering the formation of two stereogenic elements and the possible double bond migration. Therefore, the chiral ligand will be required to perform an exquisite control of both the generation of the stereogenic axis and the migratory insertion event in order to afford a satisfactory result.

\section{RESULTS AND DISCUSSION}

In a preliminary experiment, it was observed that the reaction of 2-(pyridin-2-yl)phenyl nonaflate 1a and 2,3-dihydrofuran 2 fails to give any reaction product under common Heck conditions $\left[\mathrm{Pd}(\mathrm{dba})_{2} /(R)\right.$-BINAP (cat.), DIPEA, toluene, 80 $\left.{ }^{\circ} \mathrm{C}\right]$, thus confirming our initial concerns (Scheme 2). It was assumed that the formation of a very stable $\mathbf{I}^{\mathbf{O A}}\left(\mathrm{R}=\mathrm{R}^{\prime}=\mathrm{H}\right)$ intermediate prevents coordination of the olefin and further migratory insertion. Despite this discouraging result, we envisaged that in more strained (less stable) $\mathbf{I}^{\mathbf{O A}}$ palladacycles ( $\mathrm{R}$ $=\mathrm{R}^{\prime} \neq \mathrm{H}$; e.g. from 1-(isoquinolin-1-yl)naphthalene-2-yl nonaflate $\mathbf{1 b}$ ), dissociation of the $\mathrm{N}-\mathrm{Pd}$ bond would be facilitated by release of steric strain.

Scheme 2. Preliminary experiments.

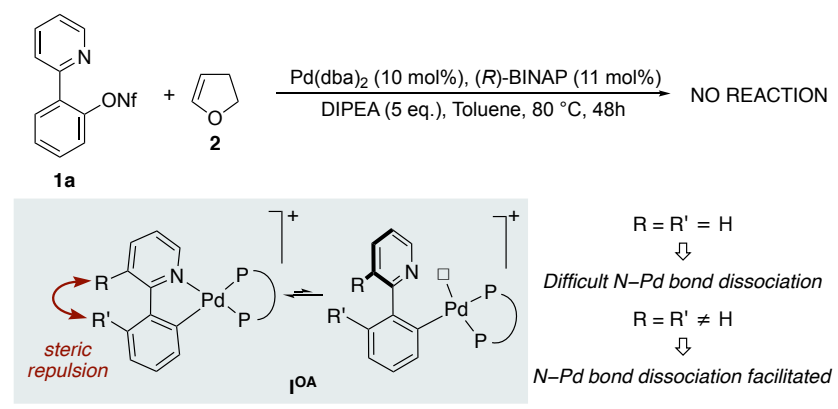

In fact, the reaction of $\mathbf{1 b}$ and $\mathbf{2}$ under the above conditions afforded the desired product as a 10:1 $\mathbf{3} \mathbf{b}: \mathbf{3} \mathbf{b} \mathbf{b}$ mixture with a promising $82 \%$ ee for the major product $3 \mathbf{b}$ (Table 1, entry 1 ). An excess of dihydrofuran was used (8 equiv.), due to the volatility of this compound. A screening of ligands and conditions was then performed to optimize this reaction [Table 1 and Table $\mathrm{S} 1$ (supporting information)]. At lower temperature $\left(60^{\circ} \mathrm{C}\right.$, entry 2$)$ the conversion dropped substantially but the enantioselectivity raised up to $88 \%$ ee. No improvements were observed using related $P, P$ ligands such as L2 (entry 3 ) or $\mathbf{L} \mathbf{3}$ (entry 4), while Josiphos derivative $\mathbf{L} \mathbf{4}$ was unproductive (entry 5). Not surprisingly, hemilabile ligand $\mathbf{L 5}$ afforded the non-isomerized Heck product $\mathbf{3}$ 'b exclusively with high diastereoselectivity, although in low ee (entry 6). Remarkably, though, ligands $\mathbf{L 6}$ or $\mathbf{L} 7$ were ineffective (entries 7 and 8); a faster alkene insertion may be favored with less $\sigma$-donating $P, N$ and $P, O$ ligands, since they form more electrophilic cationic aryl palladium(II) centers. However, a stronger binding of the pyridine/isoquinoline nitrogen is also expected in this case, preventing further coordination of the olefin.

Table 1. Screening of Reaction Conditions and Ligands.

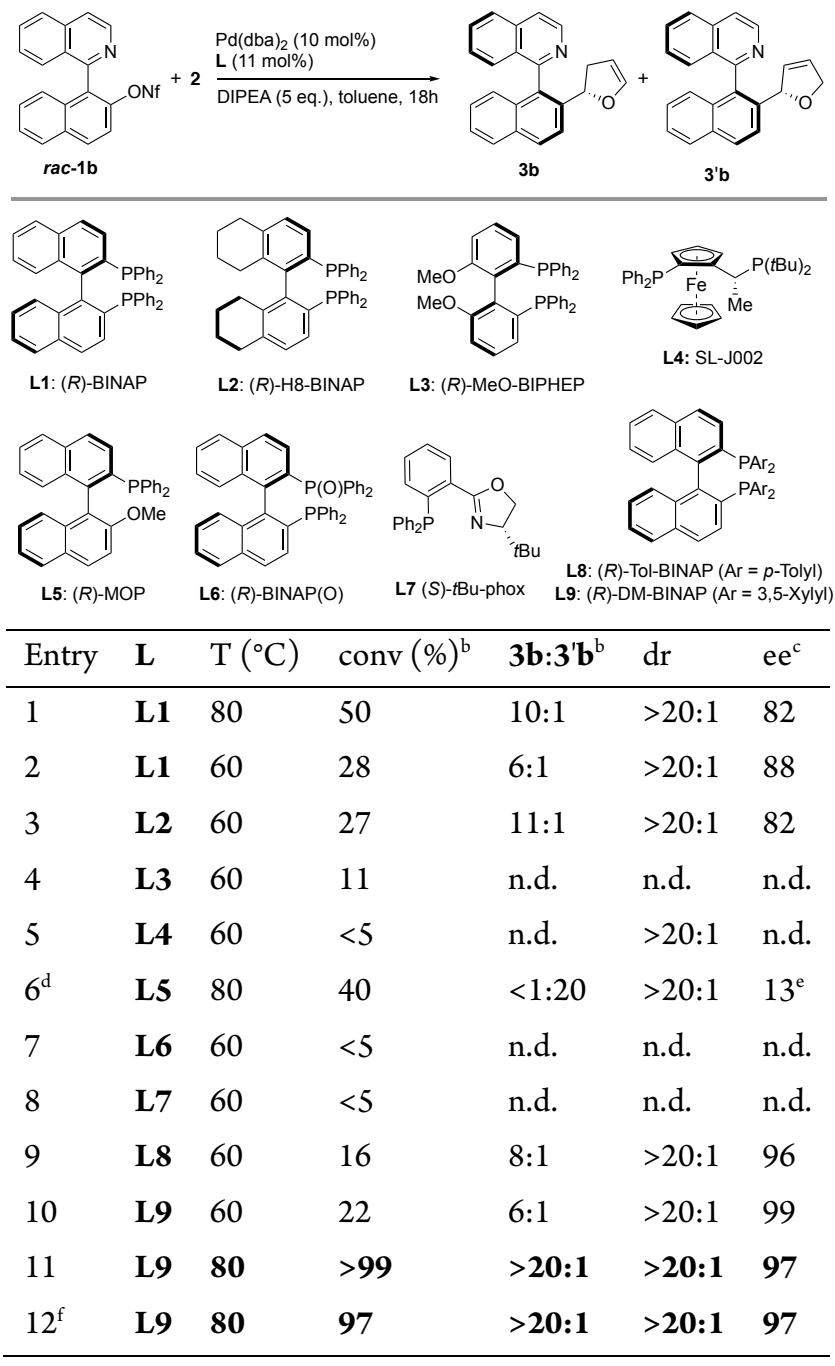

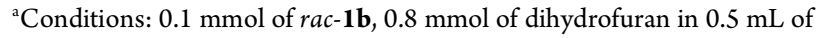
toluene. ${ }^{b}$ Determined by ${ }^{1} \mathrm{H}$ NMR spectroscopy of the crude reaction mixture. ${ }^{\mathrm{C}}$ Determined by chiral HPLC analysis. ${ }^{\mathrm{d}}$ Reaction in dioxane. ${ }^{\mathrm{e}}$ ee of $\mathbf{3} \mathbf{\mathbf { }} \mathbf{b}$ ${ }^{\mathrm{f}}[\mathrm{Pd}](5 \mathrm{~mol} \%) / \mathbf{L 9}$ (6 $\left.\mathrm{mol} \%\right)$. 
Finally, a major improvement was observed after modification of the diarylphosphino group:use of Tol-BINAP L8 and DMBINAP L9 afforded the desired product $\mathbf{3 b}$ with near perfect $\mathrm{dr}$ and ee, although the conversion remained low (entries 9 and 10). To our delight, full conversion, high diastereoselectivity ( $\mathrm{dr}>20: 1)$ and regioselectivity (>20:1) were achieved by using $\mathbf{L} 9$ at $80^{\circ} \mathrm{C}$ without significantly affecting the enantioselectivity ( $97 \%$ ee, entry 11 ). Moreover, the catalyst loading could be reduced to $5 \mathrm{~mol} \%$ to obtain a similar result (entry 12).

The Pd/DM-BINAP catalyst was successfully applied to the dynamic kinetic asymmetric Heck reaction of 2,3-dihydrofuran 2 with other heterobiaryl sulfonates, including quinazoline- (1c), phthalazine- (1d) and picoline (1e) derivatives. Different substituents at the naphthalene unit in isoquinoline derivatives $\mathbf{1 f}-\mathbf{h}$ were also tolerated (Table 2). Importantly, the method could also be extended to the reaction with $\mathrm{N}$-Boc-2,3-dihydropyrrole 4 for the synthesis of derivatives $\mathbf{5}$, although in this case DMSO proved to be the solvent of choice. Remarkably, all products $\mathbf{3}$ and $\mathbf{5}$ were obtained with excellent dr's (>20:1), along with very high ee's (up to $>99 \%$ ). Good selectivity (s) ratios, ranging from 6:1 to $>20: 1$, were observed for dihydrofuran derivatives $\left(3 / 3^{\prime}\right)$, while dihydropyrrole products were obtained in slightly lower $\mathbf{5} / \mathbf{5}^{\prime}$ selectivities $(s=3: 1$ to $6: 1)$. As a remarkable exception, and for unknown reasons, the pyrenyl $\mathbf{5}$ 'h isomer was formed exclusively, although again with an excellent diastereo- and

Table 2. Scope of Heck reactions with cyclic alkenes. ${ }^{a}$
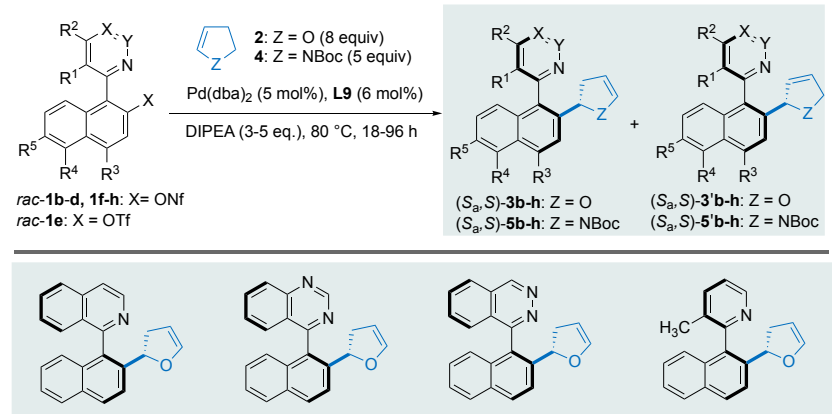

3b: $90 \%$; s >20:1; $97 \%$ ee 3 c: $92 \%$; s 14:1; $94 \%$ ee $\quad 3 d: 52 \%$; s 10:1; $90 \%$ ee $\quad$ 3e: $99 \%$; s $>20: 1 ;>99 \%$ ee
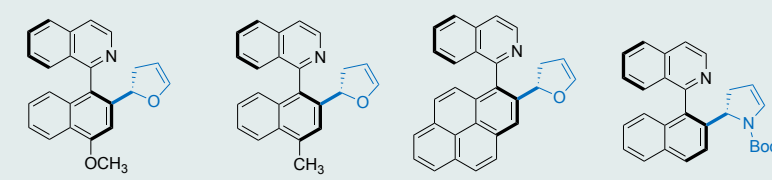

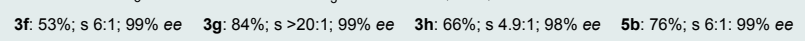
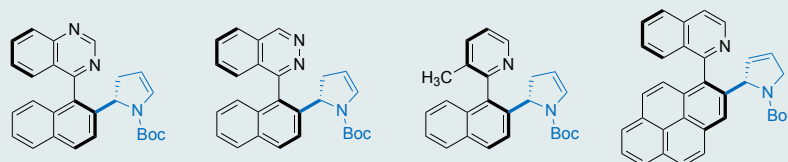

5c: $76 \%$; s 4:1; 96\% ee $\quad$ 5d:b $80 \%$; s 5:1; 98\% ee $\quad$ 5e: 70\%; s 3:1; 99\% ee $\quad$ 5'h: $60 \%$; s $<1: 20 ;>99 \%$ ee

${ }^{a}$ Reactions performed at $0.1 \mathrm{mmol}$ scale in $0.5 \mathrm{~mL}$ of solvent (toluene for 2; DMSO for 5). Isolated yields of pure major isomer after chromatography; $\mathrm{dr}^{\prime} \mathrm{s}(>20: 1$ for products $\mathbf{3}$ and $\mathbf{5}$ ) and selectivities were determined by ${ }^{1} \mathrm{H}$ NMR in the crude reaction mixtures. Ee's determined by HPLC on chiral stationary phases. 'Yield of an inseparable mixture of $\mathbf{5 d} / \mathbf{5} \mathbf{d}$.
Figure 1. X-ray structures of $\left(S_{a} S\right)$-3b and $\left(S_{a} S\right)$-5'b. Thermal ellipsoids drawn for $50 \%$ probability. $\mathrm{H}$ atoms are omitted for clarity.

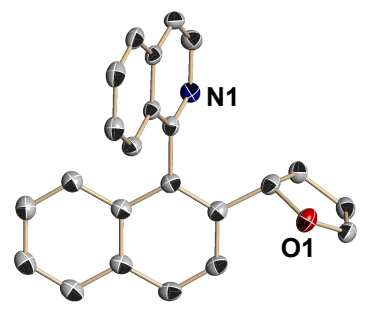

$\left(S_{a}, S\right)-\mathbf{3 b}$

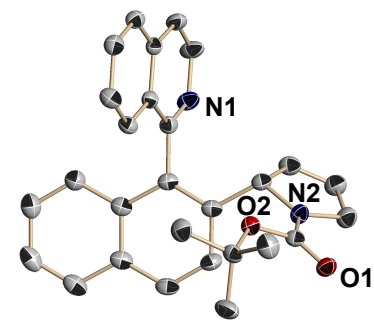

$\left(S_{a}, S\right)-5^{\prime} \mathbf{b}$ enantioselectivity. The same absolute configuration for $(S, S)$ $\mathbf{3} \mathbf{b}$ and the minor isomer $(S, S)-\mathbf{5}$ 'b were determined by X-ray diffraction analysis (Figure 1); while those of other products $\mathbf{3}$ and $\mathbf{5}$ were assigned by analogy. These data indicate that in our case there is no kinetic resolution from hydrido-alkene $\mathrm{Pd}$ complex intermediates. ${ }^{18}$ Remarkably, a similar trend has been previously reported for asymmetric Heck reactions using 3,3'-disubstituted DM-BINAP ligands. ${ }^{19}$ Not surprisingly, the reaction performed with simple cycloalkenes such as cyclopentene or cyclohexene failed to give any products, even under forcing conditions. This lack of reactivity reflects again the difficult displacement of the heterocycle $\mathrm{N}$ atom by the olefin, which requires not only some steric strain in the palladacycle but also a relatively high electron richness in the $\mathrm{C}=\mathrm{C}$ bond. Likewise, attempts to perform reactions with 5 methyl-2,3-dihydrofuran failed to give any reaction products. In this case, the lack of reactivity is attributed to the high level of steric crowding expected at the oxidative addition intermediate (see proposed mechanism below), thus preventing an effective coordination/carbometallation of hindered alkenes. Importantly, a large scale synthesis of $\mathbf{3} \boldsymbol{b}$ and $\mathbf{5} \boldsymbol{b}(1.8 \mathrm{mmol}$ and $1.5 \mathrm{mmol}$, respectively) could be performed with a lower catalyst loading (2 mol\% [Pd]; 2.4 mol\% L9) to obtain the products with similar results (3b: $81 \%$ yield, s $>20: 1, \mathrm{dr}>20: 1,97 \%$ ee; $\mathbf{5 b}$ : $60 \%$ yield (pure major isomer), s 6:1, $\mathrm{dr}>20: 1,99 \%$ ee).

We investigated also the reaction with acyclic electron rich alkenes. Unfortunately, the reaction of $\mathbf{1} \mathbf{b}$ with butyl vinyl ether $\mathbf{6}$ under the optimized conditions afforded the product $\mathbf{1 1 b}$ with a lower enantioselectivity ( $83 \%$ ee, Table S3 in the Supporting Information). However, further screening revealed that the Josiphos-type ligand $\mathbf{L} 4$ performs better in this case, reaching a satisfactory $92 \%$ ee (Table 3 ). This ligand was then used in the reactions of vinyl ethers 6-9 with heterobiaryls $\mathbf{1 b}, \mathbf{c}, \mathbf{e}$ to afford the corresponding Heck products 11-15 in high yields and enantioselectivities. On the other hand, L9 was required again in the reaction of $\mathbf{1 b}$ with vinyl acetamide $\mathbf{1 0}$ to yield product $\mathbf{1 5 b}$ in $90 \%$ yield and $82 \%$ ee. 
Table 3. Reaction Scope using Acyclic Olefins. ${ }^{a}$

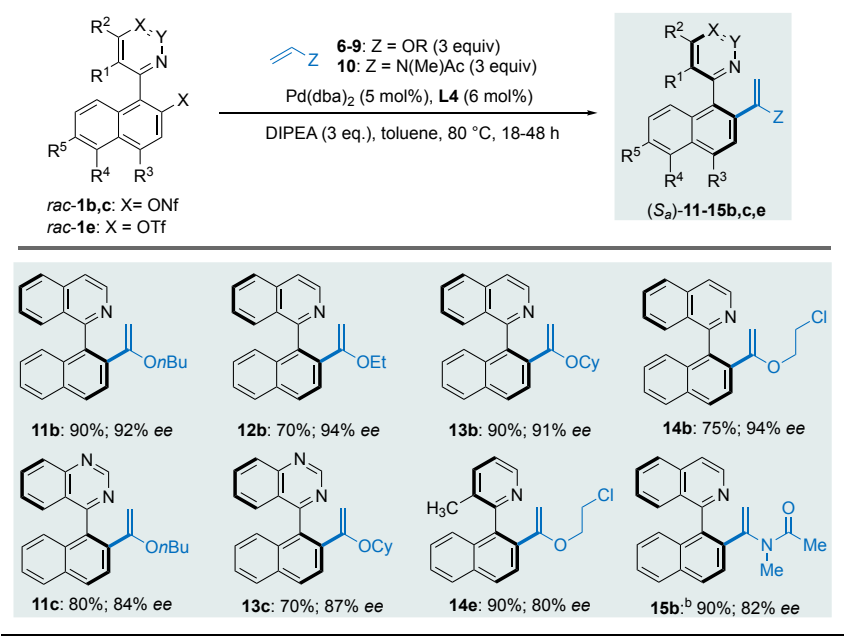

${ }^{a}$ Reactions performed at $0.1 \mathrm{mmol}$ scale in $0.5 \mathrm{~mL}$ of solvent. Ee's determined by HPLC on chiral stationary phases. ${ }^{b}$ Ligand $\mathbf{L} \mathbf{9}$ was used.

Preliminary experiments have also demonstrated that this DYKAT process can be extended to the hydroarylation of bicylic olefins (Scheme 3). Thus, reaction of $r a c-\mathbf{1 b}$ with norbornadiene in the presence of formic acid as the hydride source and $\mathbf{L} 4$ as the ligand afforded product 16 as a single diastereomer in $98 \%$ ee, although in moderate yield. Nonetheless, no double hydroarylation was observed in this transformation. The structure of ent-16. $\mathbf{H C l}^{20}$ was determined by Xray diffraction analysis, and its absolute $\left(R_{a}, S, R, R\right)$ configuration is consistent with a uniform stereochemical outcome with the Heck products $\mathbf{3}$ or $\mathbf{5}$.

Scheme 3. Hydroarylation of norbornadiene and X-ray structure of ent $-16 \cdot \mathrm{HCl}$. Thermal ellipsoids drawn for $50 \%$ probability. $\mathrm{H}$ atoms, except $\mathrm{N} \underline{\mathrm{H}}$, are omitted for clarity.
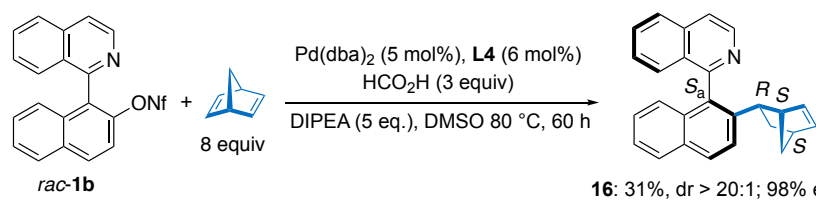

16: $31 \%, d r>20: 1 ; 98 \%$ ee
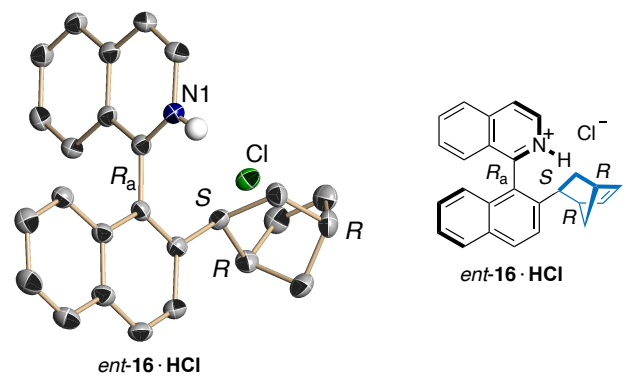

ent-16. HCI

In a control experiment, biphenyl nonaflate $\mathbf{1 7}$ was made to react with 2 under the optimized conditions to afford the expected Heck product $\mathbf{1 8}$ with high selectivity but a negligible 9\% ee (Scheme 4). This result highlights the synergistic effect between the chiral ligand and the heterobiaryl moiety
Scheme 4. Control experiments.
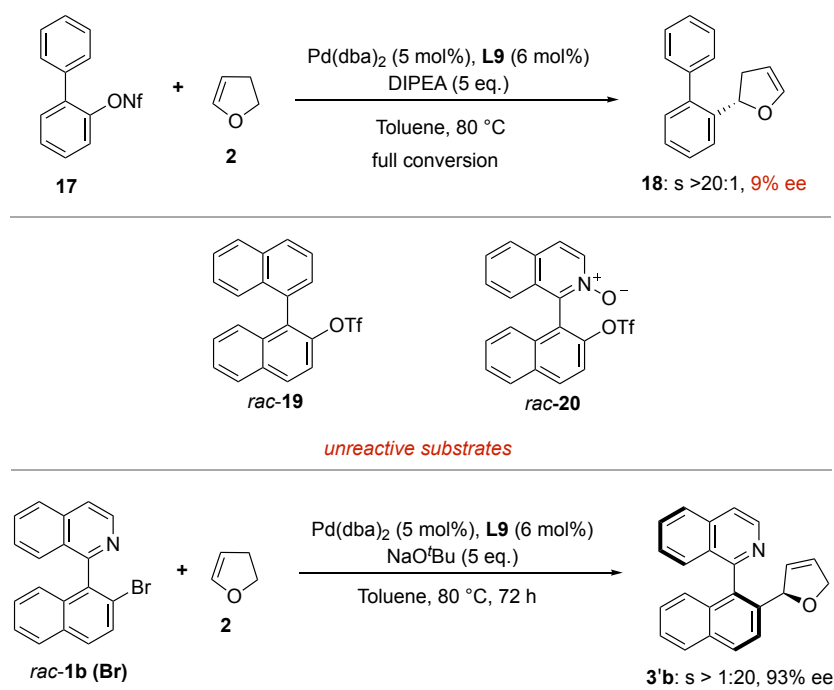

during the stereocontrolling step of the reaction. Moreover, no coupling product was formed from the more sterically demanding nonaflate $\mathrm{rac}-19$, showing that the coordinating isoquinolyl/pyridyl $\mathrm{N}$ atom is required for a facile chelate-assisted oxidative addition step. Similarly, no reaction was observed with $\mathrm{N}$-oxide $\mathrm{rac}-\mathbf{2 0}$, indicating that the formation of a five membered cationic palladacycle is also essential to reactivity. Finally, a much slower reaction was observed when 1-(2bromonaphthalen-1-yl)isoquinoline $\mathbf{1 b}(\mathbf{B r})$, in combination with $\mathrm{NaO} t \mathrm{Bu}$ as the base, was used as the starting material $\left(23 \%\right.$ conversion after $72 \mathrm{~h}$ at $\left.80^{\circ} \mathrm{C}\right)$. Interestingly, though, the non-isomerized product $\mathbf{3}^{\prime} \mathbf{b}$ was exclusively formed in 93\% ee.

We next turned to DFT studies in order to gain insight into the reaction mechanism and the origin of the high levels of enantio- and diastereoselectivity observed. We assumed that the fundamental steps of the catalytic cycle would be the oxidative addition of the racemic substrates $\mathbf{1}$ to the $\mathrm{Pd}^{0}$ catalyst leading to cationic intermediate $\mathbf{I}^{+}$, followed by transligation $(\rightarrow \mathbf{I I})$, insertion of the alkene into the $\mathrm{Pd}^{\mathrm{II}}-\mathrm{C}$ bond $(\rightarrow \mathrm{III})$, and reinstallation of the double bond in the final products 3 by $\beta$ hydride elimination $(\rightarrow \mathbf{I V})$, leading to the final products after decoordination or, eventually, double bond migration after reinsertion (hydropalladation) and a second $\beta$-hydride elimination. ${ }^{21}$ The reaction between $\mathbf{1 b}$ and $\mathbf{2}$ with the catalyst based on the optimal ligand $\mathbf{L} \mathbf{9}$ was chosen for the computational studies. Eight different isomeric products could be a priori formed by combination of the different configurations of the stereogenic axis and center, and the final position of the double bond (Figure 2). We started from diastereomeric complexes $\left(S_{\mathrm{a}}\right)-\mathbf{A}(\mathrm{G}=0)$ and $\left(R_{\mathrm{a}}\right)-\mathbf{A}(\Delta \mathrm{G}=+1.0 \mathrm{kcal} / \mathrm{mol})$ formed by coordination of both enantiomers of substrate $\mathbf{1 b}$ to the $\left[\mathrm{Pd}^{0}(\mathbf{L 9})\right]$ catalyst (Figure 3$)$. Transition states $\left(R_{\mathrm{a}}\right)$ TSO and $\left(S_{\mathrm{a}}\right)$-TSO for the oxidative addition step were located for both atropoisomers at $\Delta \mathrm{G}^{\ddagger}=18.4$ and $32.4 \mathrm{kcal} / \mathrm{mol}$, 
Figure 2. Proposed mechanism. Shaded structures are drawn for pathways leading to non-detected products.

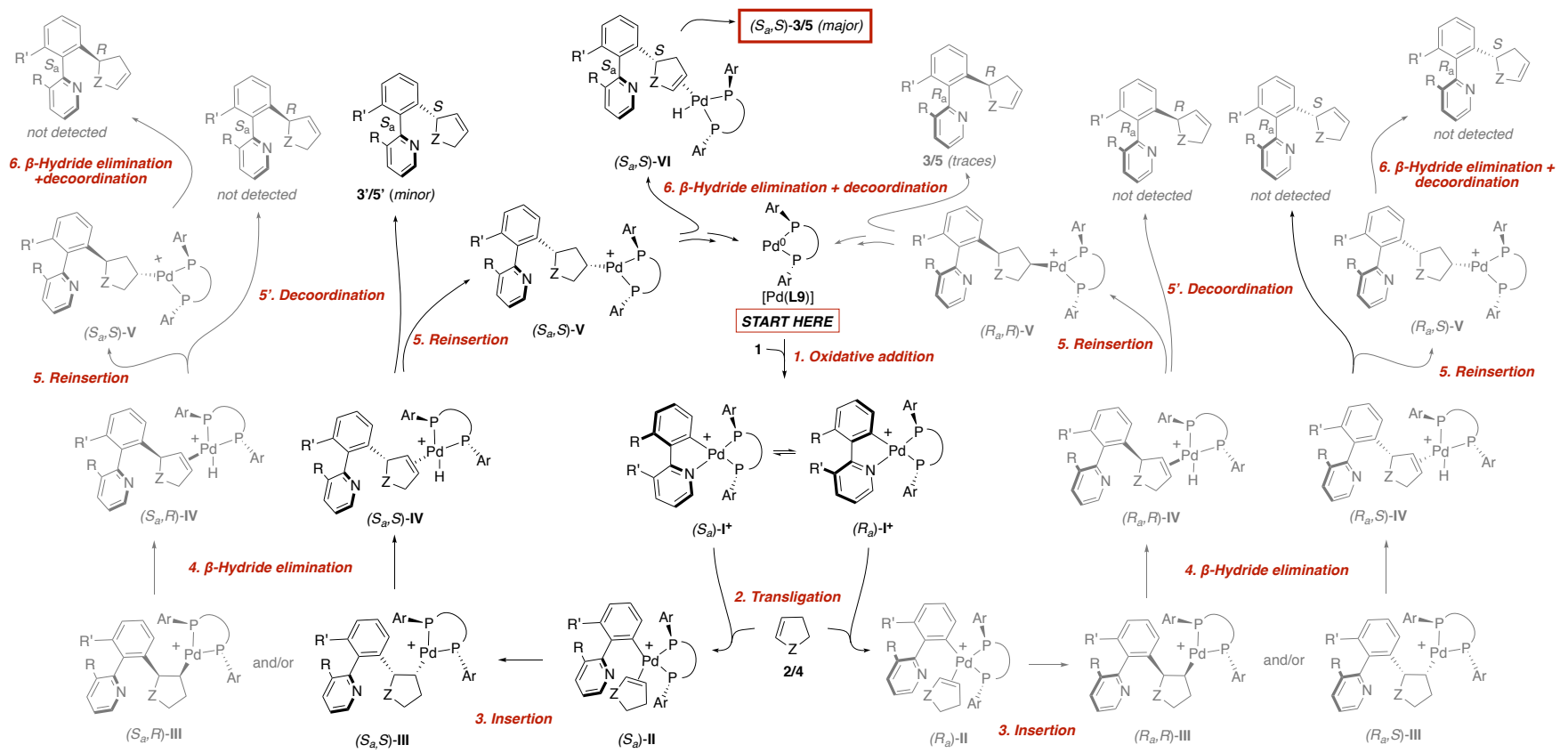

Figure 3. Formation of cationic intermediates $\mathbf{I}^{+}$and computed energies.

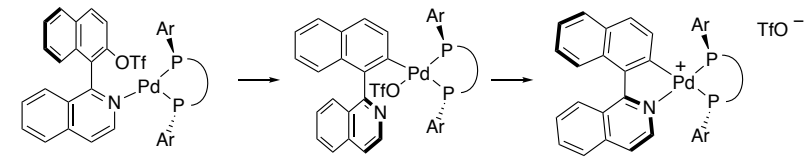

$\left(S_{a}\right)-\mathbf{A}$

$\left(S_{a}\right)-1$

$\left(S_{a}\right)-I^{+}$
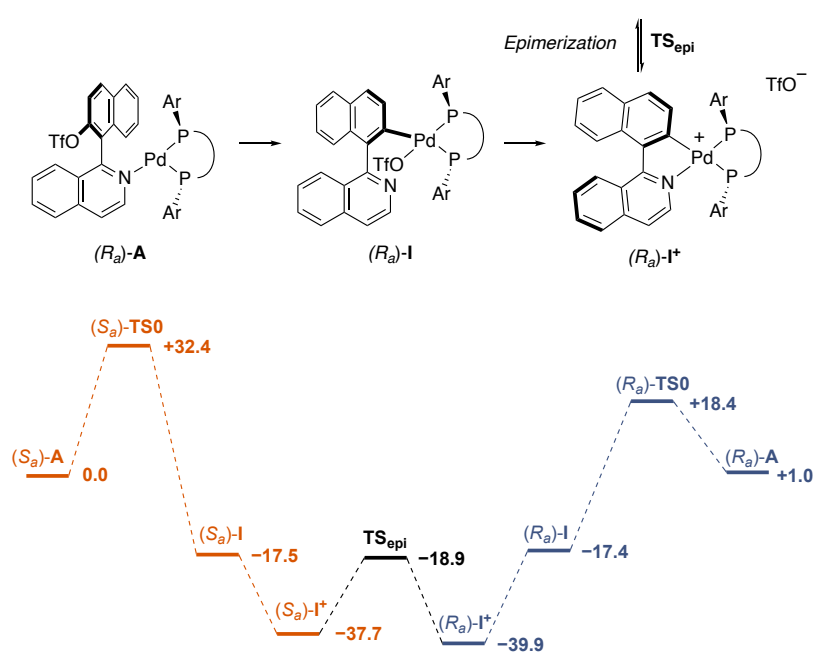

respectively, leading to intermediates $\left(S_{\mathrm{a}}\right)-\mathbf{I}$ and $\left(R_{\mathrm{a}}\right)$-I of similar energies $(\Delta \mathrm{G}=-17.5$ and $-17.4 \mathrm{kcal} / \mathrm{mol})$. As expected, displacement of the triflate by the isoquinoline $\mathrm{N}$ atom to form cationic intermediates $\left(S_{\mathrm{a}}\right)-\mathbf{I}^{+}$and $\left(R_{\mathrm{a}}\right)-\mathbf{I}^{+}$provides an additional stabilization of 20.2 and $22.5 \mathrm{kcal} / \mathrm{mol}$, respectively (Figure 3 ). To make possible an efficient dynamic kinetic resolution, these diastereomeric $\mathrm{Pd}(\mathrm{II})$ intermediates have to interconvert in a fast equilibrium and the subsequent steps must present different activation barriers for the different diastereomeric transition states. In fact, the low barrier computed for this epimerization $\left(\mathbf{T S}_{\text {epi }}: \Delta \mathrm{G}^{\ddagger}=\right.$ $21.0 \mathrm{kcal} / \mathrm{mol}$ ) demonstrates the feasibility of the rotation around the chiral axis at this point. ${ }^{22}$ As expected, the coordination of the dihydrofuran substrate $\mathbf{2}$ to form intermediates II in the next step requires decoordination of the isoquinoline $\mathrm{N}$ atom, and rotation of the biaryl group above or below the coordination plane. Surprisingly, the calculations indicate that the ligand exchange is concerted: in the located transition states TS1, the dihydrofuran molecule is moving into the coordination sphere of palladium as the same time as the isoquinoline is rotating away from the metal center (Figure 4). In $\left(S_{\mathrm{a}}\right)$-TS1, for example, the Pd-N and Pd-alkene distances are $3.2 \AA$ and $3.7 \AA$ respectively. During this process, the ligands are moving in a very sterically crowded environment, inducing a significant activation barrier of $\Delta \mathrm{G}^{\ddagger}$ $=23.2 \mathrm{kcal} / \mathrm{mol}$ for $\left.\left(R_{\mathrm{a}}\right)-\mathbf{T S 1}\right)$. In the following alkene insertion into the $\mathrm{C}$ (Aryl)-Pd bond, eight different transition states (TS2) were located for the four forming diastereomers and two possible orientations for the isoquinoline ring (above or below the coordination plane) in each case. Noteworthy, some of them present relatively low free activation energies, with a minimum of $\Delta G^{\ddagger}=21.3 \mathrm{kcal} / \mathrm{mol}$ for $\left(R_{\mathrm{a}}, R\right)$-TS2, which is actually lower than that of the previous step $\left[\left(R_{a}\right)\right.$-TS1]. The highest activation energy $\left(\Delta G^{\ddagger}=\right.$ 27.7) corresponds to $\left(S_{\mathrm{a}}, S\right)$-TS2, in sharp contrast with the experimental results (obtention of $S_{\alpha} S$ as the major stereoisomer, with high levels of selectivity). These inconsistencies suggest that TS2 might not be the rate determining nor the stereocontrolling step, which should therefore be located at a later stage in the catalytic cycle. In this regard, the reaction evolves through TS3 to reinstall the alkene functionality 
Figure 4. Computed energies for key intermediates and transition states performed at the M06/def2tzvpp//B3LYP/6-31G(d,p) (Pd,SDD) (IEFPCM,toluene) level. Selected 3D structures are illustrated using CYLview. ${ }^{23}$
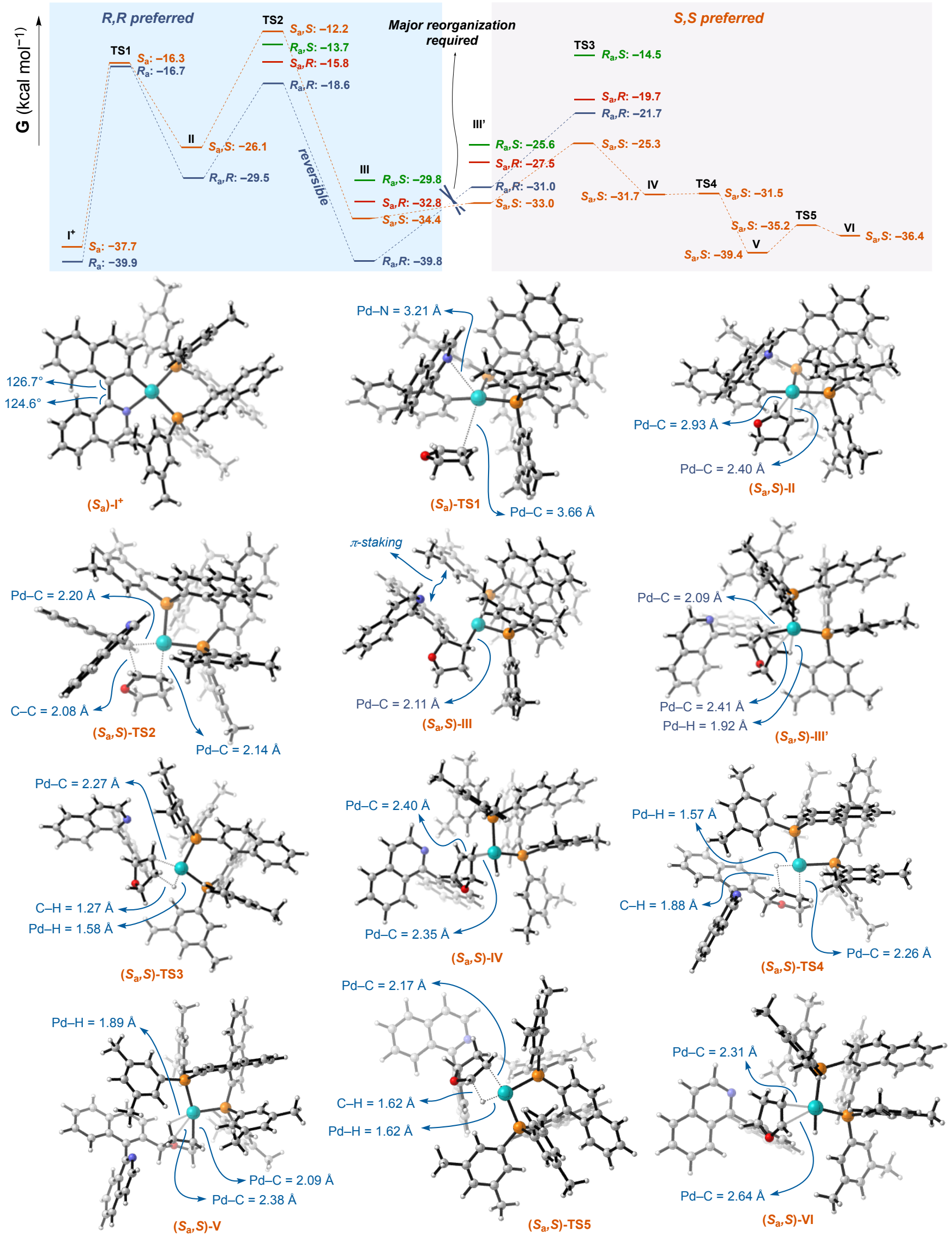
after a $\beta$-hydride elimination. We were pleased to find that this step also presents a notable activation barrier, especially due to the high stability of the insertion intermediate III. Interestingly enough, the isomer preference reverses at this point, and $\left(S_{\mathrm{a}}, S\right)$-TS3 becomes the most favored diastereomer $\left(\Delta G^{\ddagger}=14.6 \mathrm{kcal} / \mathrm{mol}\right)$, in fair agreement with the experimental results. Moreover, the $\left(R_{\mathrm{a}}, S\right)$-TS3 or $\left(S_{\mathrm{a}}, R\right)$ - TS3, leading to experimentally undetected products are the highest in energy $\left(\Delta G^{\ddagger}=25.4\right.$ and $20.2 \mathrm{kcal} / \mathrm{mol}$, respectively), while $\left(R_{\mathrm{a}}, R\right)$-TS3 has an activation barrier of $\Delta \mathrm{G}^{\ddagger}=18.2 \mathrm{kcal} / \mathrm{mol}$, accounting for the high levels of enantioselectivity observed. For these reasons, TS3 becomes a solid candidate to be the stereo-determining step of the reaction. This proposal requires that TS2 is a reversible step, and indeed, the barrier for the reversion from $\left(R_{\mathrm{a}}, R\right)$-III to $\left(R_{\mathrm{a}}, R\right)$-TS2 shows an affordable energy of $21.4 \mathrm{kcal} / \mathrm{mol}$.

On the other hand, the inspection of the structure of the elimination transition states (TS3) indicates that they cannot be directly accessed from the previous III-type intermediates. A large reorientation and rotation of the biaryl moiety must take place to prepare the substrate for the $\beta$-hydride elimination. Indeed, a second intermediate structure III' was located, presenting an agostic interaction of palladium with the adjacent $\mathrm{C}-\mathrm{H}$ bond, immediately preceding the $\beta$-elimination. The participation of intermediates III and III' in the mechanism could be also confirmed through forward and backward IRC calculations starting from TS2 and TS3 respectively. Unfortunately, any attempts to find suitable transition state(s) for the conversion of intermediates III into III' were unsuccessful, but a comparative analysis of their structures reveals that a major reorganization in a sterically very crowded environment is required. Remarkably, this reorganization appears to be particularly complex for the $(R, R)$ isomer. For instance, change in the $\mathrm{P}_{\text {syn }}-\mathrm{Pd}-\mathrm{C}_{3 \text { (furane) }}-\mathrm{C}_{4 \text { (furane) }}$ dihedral angle serves as an illustrative index: it moves from $66.6^{\circ}$ in $\left(R_{a} R\right)$-III to $150.5^{\circ}$ in $\left(R_{a}, R\right)$-III', while the same rotation in the $\left(S_{a}, S\right)$ series is significantly shorter (from $-93.0^{\circ}$ to $-144^{\circ}$ ) (Figure 5). Furthermore, a potential energy surface scan was performed for the variation of the dihedral angle in $\left(S_{a}, S\right)$-III from $93^{\circ}$ to $144^{\circ}$ without any noticeable limitation, while the angle in $\left(\mathrm{R}_{a}, R\right)$-III presents a rotation restricted to the interval between $67^{\circ}$ and $110^{\circ}$ due to the steric collision between the quinoline and the aryl phosphine moieties at that point. To complete the rotation, the phospines must move largely aside with the accompanying energetic cost.

From this point forward, intermediates IV evolve to either the minor products 3 ' by decoordination or, after reinsertion $[\rightarrow \mathbf{V}$ via TS4 $]$ and a second $\beta$-hydride elimination $[\rightarrow \mathbf{V I}$ via TS5], the major (or unique) products 3 . The calculated activation energies for these last steps are very low $\left(\Delta G^{\ddagger}=0.2\right.$ and $4.2 \mathrm{kcal} / \mathrm{mol}$ for $\left(S_{\mathrm{a}}, S\right)$-TS4 and $\left(S_{\mathrm{a}}, S\right)$-TS5, respectively) and, therefore, they don't have any influence on the stereochemical outcome of the reaction.
Figure 5. Comparison of intermediates III and III' in the $\left(R_{a} R\right)$ and $\left(S_{a} S\right)$ series. Ligand omitted for the sake of clarity.

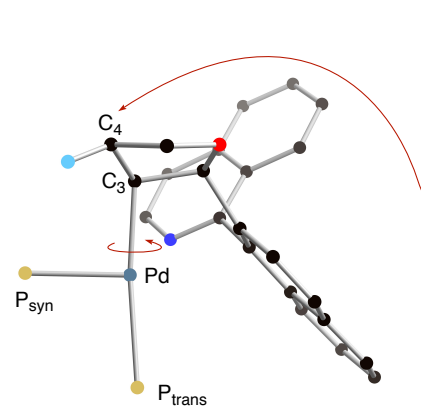

$\left(R_{a}, R\right)$-III

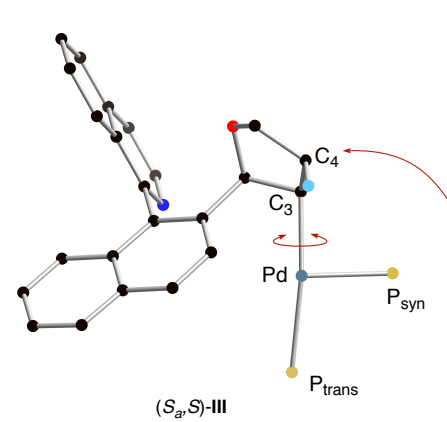

$\left(S_{a}, S\right)$-III

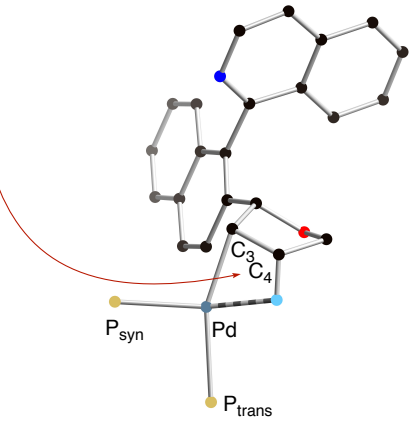

$\left(R_{a}, R\right)-$-III'

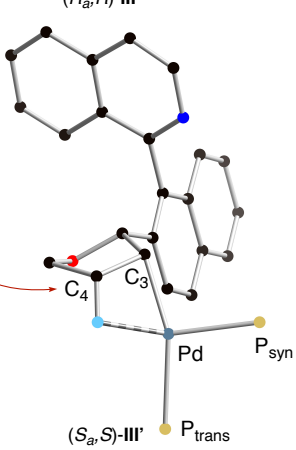

Summarizing, the combination of the reversibility of TS2, at least for some of the isomers, together with the large energy difference between the isomeric TS3 transition states and a difficult reorganization from III to III' can explain the preferential formation of the $S_{a} S$ isomer. This unprecedented mechanistic profile appears to be governed by the heterobiaryl moiety: in reactions with simple aryl triflates, the insertion step appears to be the stereodetermining one. Consequently, the use or $\left(R_{\mathrm{a}}\right)-\mathrm{BINAP}^{18}$ or $\left(R_{\mathrm{a}}\right)$-DM-BINAP ${ }^{19}$ as the ligands in this case results in the formation of major products with the $R$ configuration in low to moderate enantiomeric excesses. $^{24}$

In the reaction of $\mathbf{1 b}(\mathbf{B r})$, it is assumed that the precipitation of $\mathrm{NaBr}$ in toluene causes a ligand exchange $\left(\mathrm{Br} \rightarrow \mathrm{O}^{\mathrm{t}} \mathrm{Bu}\right) .^{14 \mathrm{~d}}$ Therefore, the main difference with the original reaction from $\mathbf{l b}$ is the basicity and coordination ability of the counteranion ( $\mathrm{O}^{t} \mathrm{Bu}$ versus $\left.\mathrm{OTf}\right)$. According to the proposed mechanism, the poor reactivity observed for $\mathbf{l b}(\mathbf{B r})$ is then explained by the lower concentration of the reactive intermediate II, in equilibrium with the unproductive neutral species II $\left(\mathbf{O}^{t} \mathbf{B u}\right)$ (Scheme 5). Similarly, the exclusive formation of $\mathbf{3}$ 'b can tentatively be attributed to a fast deprotonation of the intermediate $\left(S_{\mathbf{a}}, S\right)-\mathbf{I V}\left(\mathbf{O}^{t} \mathbf{B u}\right)$ with respect of the reinsertion of the hydride. 
Scheme 5. Singularities in the reaction of $1 \mathbf{b}(\mathrm{Br})$ with 2 .
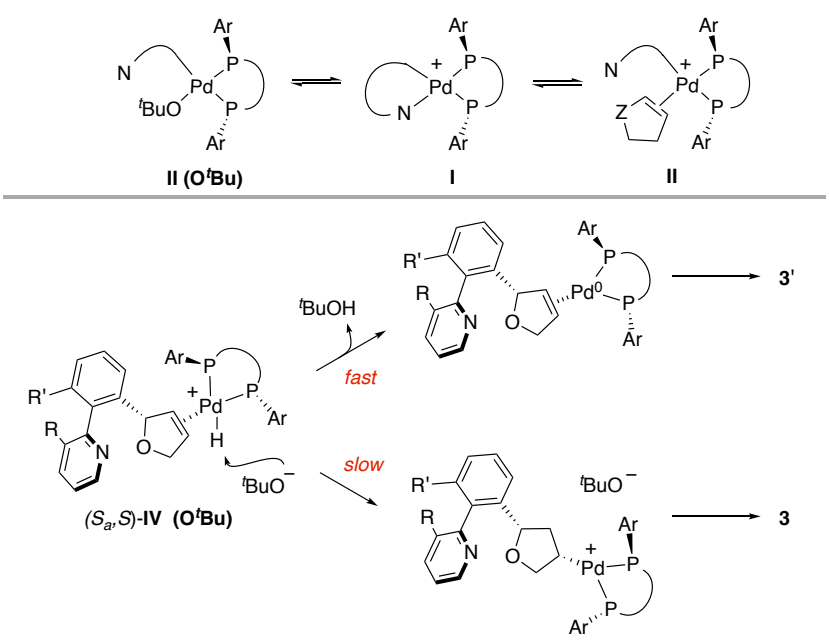

Several attempts to obtain and characterize the cationic oxidative addition intermediate $\mathbf{I}^{+}$with the optimal ligand $\left(R_{\mathrm{a}}\right)$ DM-BINAP L9 were unsuccessful. We hypothesized that the very high steric crowding in this intermediate could be responsible for its instability. $\left(R_{\mathrm{a}}\right)$-BINAP $\mathbf{L} \mathbf{1}$ is a very similar ligand that provided also good reactivity and selectivity, but the corresponding intermediate has a lower steric demand around the $\mathrm{Pd}$ center. In fact, equimolar amounts of $[\mathrm{Pd}(\mathrm{Cp})($ allyl $)]$ as the $\mathrm{Pd}^{0}$ precursor, rac-1b(OTf) and $\mathbf{L 1}$ cleanly reacted to afford the expected intermediate $\mathbf{I}_{\mathbf{L} 1}(\mathbf{O T f})$ as a relatively stable, crystalline compound whose structure was unequivocally confirmed by X-ray diffraction analysis (Figure 6). Interestingly, the stereogenic axis in the solid state shows the same $\left(R_{\mathrm{a}}\right)$ configuration as the most stable calculated intermediate $\left(R_{\mathrm{a}}\right)-\mathbf{I}^{+}$. Nevertheless, the stoichiometric reaction of this isolated intermediate with dihydrofuran $\mathbf{2}$ in toluene at $80{ }^{\circ} \mathrm{C}$ afforded the product $\left(S_{\mathrm{a}}, S\right)$-3a in $82 \%$ yield and $77 \%$ ee.

Figure 6. Synthesis of $\mathbf{I}_{\mathbf{L 1}}(\mathbf{O T f})$ and ORTEP drawing of the cation $\mathbf{I}_{\mathbf{L 1}}{ }^{+}$.

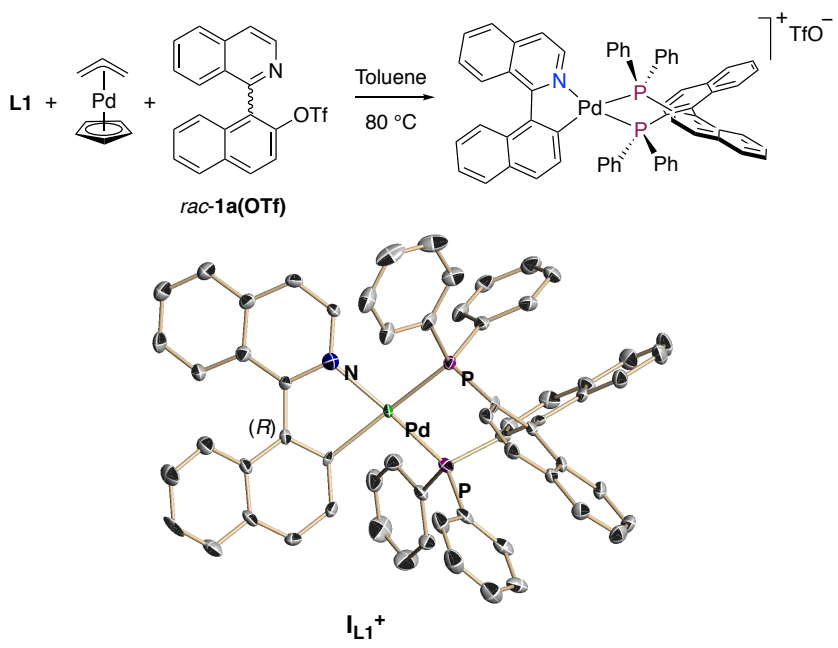

In order to illustrate the synthetic utility of the methodology, compound $\mathbf{5 b}$ was subjected to N-Boc deprotection with TFA and the resulting cyclic imine $\mathbf{2 1}$ was employed as ligand for the synthesis of the chiral Pd ${ }^{\mathrm{II}}$ (allyl) complex 22 (Scheme 6). Additionally, reduction of the imine group of 21 with $\mathrm{NaBH}_{4}$ afforded bifunctional pyrrolidine derivative 23 possessing appealing structural characteristics for its use in asymmetric organocatalysis. Importantly, no epimerization was observed in any of these transformations.

Scheme 6. Representative transformations from $\mathbf{5 b}$.

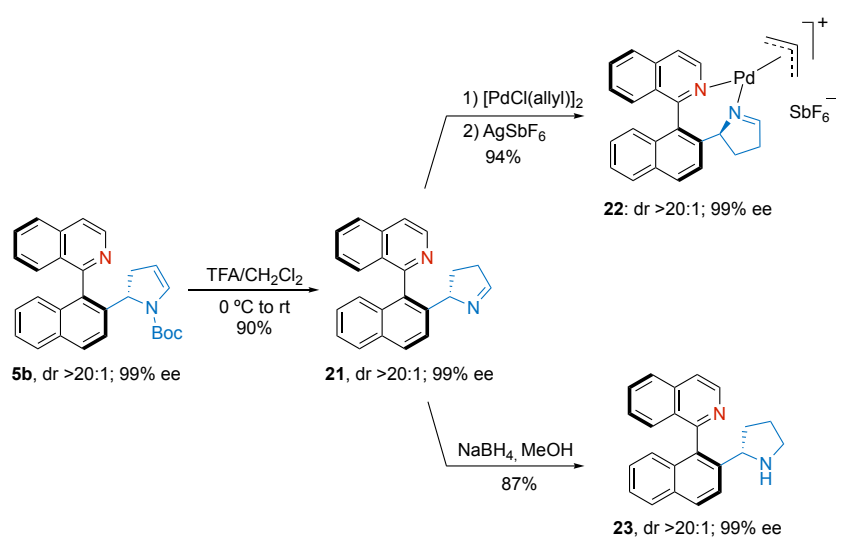

\section{CONCLUSION}

In summary, we have developed a highly regio-, diastereo and enantioselective dynamic kinetic asymmetric Heck reaction of racemic heterobiaryl sulfonates with electron-rich olefins. This transformation represents the first example of the use of an asymmetric Heck reaction to resolve both a stereogenic axis and a stereocenter simultaneously, showing a broad scope of axially chiral heterobiaryl compounds with electronrich cyclic and acyclic olefins using $\mathbf{L} \mathbf{9}$ and $\mathbf{L 4}$, respectively. Facile stereoretentive transformations led to appealing axially chiral heterobiaryl complexes and bifunctional organocatalysts whose applications are currently under investigation in our laboratories.

\section{ASSOCIATED CONTENT}

The Supporting Information is available free of charge on the ACS Publications website.

Experimental procedures, optimization studies, characterization data, NMR spectra for new compounds, and HPLC traces (PDF).

Crystallographic data for $\left(S_{\mathrm{a},}, S\right)-\mathbf{3 b}$ (CIF)

Crystallographic data for $\left(S_{a}, S\right)-5$ 'b $\mathbf{b}$ (CIF)

Crystallographic data for ent-16.HCl (CIF)

Crystallographic data for $\mathbf{I}_{\mathbf{L 1}}$ (OTf) (CIF)

Detailed computational study. Calculated structures and energies (PDF)

Three-dimensional structural data of $\left(S_{\mathrm{a}}\right)$-A (PDB)

Three-dimensional structural data of $\left(R_{\mathrm{a}}\right)-\mathrm{A}(\mathrm{PDB})$

Three-dimensional structural data of $\left(S_{\mathrm{a}}\right)$-TSO (PDB)

Three-dimensional structural data of $\left(R_{\mathrm{a}}\right)$-TSO $(\mathrm{PDB})$ 
Three-dimensional structural data of $\left(S_{\mathrm{a}}\right)$-I $(\mathrm{PDB})$ Three-dimensional structural data of $\left(R_{\mathrm{a}}\right)$-I $(\mathrm{PDB})$ Three-dimensional structural data of $\left(S_{\mathrm{a}}\right)-\mathbf{I}^{+}(\mathrm{PDB})$ Three-dimensional structural data of $\left(R_{\mathrm{a}}\right)-\mathbf{I}^{+}(\mathrm{PDB})$ Three-dimensional structural data of $\mathbf{T S}_{\text {epi }}(\mathrm{PDB})$ Three-dimensional structural data of $\left(S_{\mathrm{a}}\right)$-TS1 (PDB) Three-dimensional structural data of $\left(S_{a}, S\right)$-II (PDB) Three-dimensional structural data of $\left(S_{a} S\right)$-TS2 (PDB) Three-dimensional structural data of $\left(S_{a}, S\right)$-III(PDB) Three-dimensional structural data of $\left(S_{a}, S\right)$-III'(PDB) Three-dimensional structural data of $\left(R_{y} R\right)$-III(PDB) Three-dimensional structural data of $\left(R_{\mathrm{a}}, R\right)$-III'(PDB) Three-dimensional structural data of $\left(S_{\mathrm{a}}, S\right)$-TS3 (PDB) Three-dimensional structural data of $\left(S_{a} S\right)$-IV (PDB) Three-dimensional structural data of $\left(S_{\mathrm{a}}, S\right)$-TS4 (PDB) Three-dimensional structural data of $\left(S_{a} S\right)-\mathbf{V}(\mathrm{PDB})$ Three-dimensional structural data of $\left(S_{a} S\right)$-TS5 (PDB) Three-dimensional structural data of $\left(S_{a}, S\right)$-VI (PDB)

\section{AUTHOR INFORMATION}

\section{Corresponding Author \\ *vhornillos@iiq.csic.es. \\ *ffernan@us.es. \\ *jmlassa@iiq.csic.es.}

\section{Notes}

The authors declare no competing financial interests

\section{ACKNOWLEDGMENT}

Dedicated to Professor Miguel Yus on the occasion of his 70th birthday. We thank the Spanish Ministerio de Ciencia e Innovación (Grants CTQ2016-76908-C2-1-P, CTQ2016-76908C2-2-P, CTQ2016-78083-P and contract RYC-2013-12585 for A.R.), European funding (ERDF), Junta de Andalucía (Grant 2012/FQM 10787 and fellowship for J. A. C.). VH thanks the Junta de Andalucía and the European Union's Seventh Framework Program, Marie Skłodowska-Curie actions for a Talent Hub fellowship (COFUND - Grant Agreement no 291780) and the University of Seville for a research grant (no 1800511201). E.G.-B. thanks IZO-SGI SGIker of UPV-EHU for human and technical support. We also thank Prof. Celia Maya for assistance with the X-ray crystallographic studies.

\section{REFERENCES}

(1) Reviews: (a) Heck, R. F. Acc. Chem. Res. 1979, 12, 146. (b) The Mizoroki-Heck Reaction; Oestreich, M., Ed.; Wiley: New York, 2009. (c) Bräse, S.; de Meijere, A. In Metal-Catalyzed Cross-Coupling Reactions; de Meijere, A., Diederich, F., Eds.; Wiley-VCH: Weinheim, 2014; pp 533-633.

(2) Ozawa, F.; Kubo, A.; Hayashi, T. J. Am. Chem. Soc. 1991, 113, 1417.

(3) Reviews: (a) Loiseleur, O.; Hayashi, M.; Keenan, M.; Schmees, N.; Pfaltz, A. J. Organomet. Chem. 1999, 576, 16. (b) Tietze, L. F.; Ila, H.; Bell, H. P. Chem. Rev . 2004, 104, 3453. (c) McCartney, D.; Guiry, P. J. Chem. Soc. Rev. 2011, 40, 5122. (d) Shibasaki, M.; Vogl, E. M.; Ohshima, T. Adv. Synth. Catal. 2004, 346, 1533.

(4) (a) Wöste, T. H.; Oestreich, M. Chem. Eur. J. 2011, 17, 11914. (b) Hu, J.; Hirao, H.; Li, Y.; Zhou, J. Angew. Chem. Int. Ed. 2013, 52, 8676. (c) Hu, J.; Lu, Y.; Li, Y.; Zhou, J. Chem. Commun. 2013, 49, 9425. (d) Liu, S.; Zhou, J. Chem. Commun. 2013, 49, 11758. (e) Oestreich, M. Angew. Chem. Int. Ed. 2014, 53, 2282.
(5) Yang, Z.; Zhou, J. J. Am. Chem. Soc. 2012, 134, 11833.

(6) Wu, C.; Zhou, J. J. Am. Chem. Soc. 2014, 136, 650.

(7) (a) Borrajo-Calleja, G. M.; Bizet, V.; Bürgi, T.; Mazet, C. Chem. Sci. 2015, 6, 4807. (b) Zhang, Q.-S.; Wan, S.-L.; Chen, D.; Ding, C.-H.; Hou, X.L. Chem. Commun., 2015, 51, 12235 .

(8) (a) Werner, E. W.; Mei, T.-S.; Burckle, A. J.; Sigman, M. S. Science 2012, 338, 1455. (b) Oliveira, C. C.; Angnes, R. A.; Correia, C. R. D. J. Org. Chem. 2013, 78, 4373. (c) Oliveira, C. C.; Pfaltz, A.; Correia, C. R. D. Angew. Chem. Int. Ed. 2015, 54, 14036.

(9) Zhang, C.; Santiago, C. B.; Kou, L.; Sigman M. S. J. Am. Chem. Soc. 2015, 137, 7290.

(10) (a) Mei, T.-S.; Werner, E. W.; Burckle, A. J.; Sigman, M. S. J. Am. Chem. Soc. 2013, 135, 6830. (b) Mei, T.-S.; Patel, H. H.; Sigman, M. S. Nature 2014, 508, 340. (c) Zhang, C.; Santiago, C. B.; Crawford, J. M.; Sigman, M. S. J. Am. Chem. Soc. 2015, 137, 15668 (d) Chen, Z. M.; Hilton, M. J.; Sigman, M. S. J. Am. Chem. Soc. 2016, 138, 11461.

(11) Lapierre, A. J. B.; Geib, S. J.; Curran, D. P. J. Am. Chem. Soc. 2007, 129, 494. (b) Guthrie, D. B.; Geib, S. J.; Curran, D. P. J. Am. Chem. Soc. 2011, 133, 115.

(12) Selected reviews: (a) Cherney, A. H.; Kadunce, N. T.; Reisman, S. E. Chem. Rev. 2015, 115, 9587. (b) Zhang, D.; Wang , Q. Coord. Chem. Rev. 2015, 286, 1. (c) Pauline, L.; Manoury, E.; Poli, R.; Deydier, E.; Labande, A. Coord. Chem. Rev. 2016, 308, 131

(13) Selected reviews: (a) Ma, G.; Sibi, M. P. Chem. Eur. J. 2015, 21, 11644. (b) Wencel-Delord, J.; Panossian, A.; Leroux, F. R.; Colobert, F. Chem. Soc. Rev. 2015, 44, 3418. (c) Tanaka, K. Chem. Asian J. 2009, 4, 508. Selected examples: (d) Gao, D.-W.; Gu, Q.; You, S.-L. ACS Catal. 2014, 4, 2741. (e) Staniland, S.; Adams, R. W.; McDouall, J. J. W.; Maffucci, I.; Contini, A.; Grainger, D. M.; Turner, N. J.; Clayden, J. Angew. Chem. Int. Ed. 2016, 55, 10755. (f) Zheng, J.; You, S.-L. Angew. Chem. Int. Ed. 2014, 53, 13244.

(14) (a) Ros, A.; Estepa, B.; Ramírez-López, P.; Álvarez, E.; Fernández, R.; Lassaletta, J. M. J. Am. Chem. Soc. 2013, 135, 15730. (b) Ramírez-López, P.; Ros, A.; Estepa, B.; Fernández, R.; Fiser, B.; Gómez-Bengoa, E.; Lassaletta, J. M. ACS Catal. 2016, 6, 3955. (c) See also: Bhat, V.; Wang, S.; Stoltz, B. M.; Virgil, S. C. J. Am. Chem. Soc. 2013, 135, 16829. (d) RamírezLópez, P.; Ros, A.; Romero-Arenas, A.; Iglesias-Sigüenza, J.; Fernández, R.; Lassaletta, J. M. J. Am. Chem. Soc. 2016, 138, 12053. (e) Hornillos, V.; Ros, A.; Ramírez-Lopez, P.; Iglesias- Sigüenza, J.; Fernández, R.; Lassaletta, J. M. Chem. Commun. 2016, 52, 14121.

(15) Selected examples: (a) Denmark, S. E.; Fan, Y. Tetrahedron: Asymmetry 2006, 17, 687. (b) Nareddy, P.; Mantilli, L.; Guenée, L.; Mazet, C. Angew. Chem. Int. Ed. 2012, 51, 3826. (c) Shibatomi, K.; Soga, Y.; Narayama, A.; Fujisawa, I.; Iwasa, S. J. Am. Chem. Soc. 2012, 134, 9836. (d) Wang, S.; Li, J.; Miao, T.; Wu, W.; Li, Q.; Zhuang, Y.; Zhou, Z.; Qiu, L. Org. Lett. 2012, 14, 1966. (e) Bai, X.-F.; Song, T.; Xu, Z.; Xia, C.-G.; Huang, W. S.; Xu, L.-W. Angew. Chem. Int. Ed. 2015, 54, 5255. (f) Zhang, J.-W.; Xu, J.-H.; Cheng, D.J.; Shi, C.; Liu, X.-Y.; Tan, B. Nat. Commun. 2016, 7, 10677. (g) Race, N. J.; Faulkner, A.; Fumagalli, G.; Yamauchi, T.; Scott, J. S.; Rydén-Landergren, M.; Sparkes H. A.; Bower; J. F. Chem. Sci. 2017, 8, 1981.

(16) (a) Rios, R.; Jimeno, C.; Carroll, P. J.; Walsh, P. J. J. Am. Chem. Soc. 2002, 124, 10272. (b) Shibata, T.; Otomo, M.; Tahara, Y.; Endo, K. Org. Biomol. Chem. 2008, 6, 4296. (c) Iorio, N. D.; Righi, P.; Mazzanti, A.; Mancinelli, M.; Ciogli, A.; Bencivenni, G. J. Am. Chem. Soc. 2014, 136, 10250. (d) Liu, H.-C.; Tao, H.-Y.; Cong, H.; Wang, C.-J. J. Org. Chem. 2016, 81, 3752. (e) Yang, Y.; Liu, H.; Peng, C.; Wu, J.; Zhang, J.; Qiao, Y.; Wang, X.-N.; Chang, J. Org. Lett. 2016, 18, 5022. (f) Borie, C.; Vanthuyne, N.; Bertrand, M. P.; Siri, D.; Nechab, M. ACS Catal. 2016, 6, 1559. (g) Min, C.; Lin, Y.; Seidel, D. Angew. Chem. Int. Ed. 2017, 56, 15353. (h) Liu, Y.; Tse, Y.-L. S.; Kwong, F. Y.; Yeung, Y.-Y. ACS Catal. 2017, 7, 4435.

(17) Knowles, J. P.; Whiting, A. Org. Biomol. Chem. 2007, 5, 31.

(18) Ozawa, F.; Kubo, A.; Matsumoto, Y.; Hayashi, T.; Nishioka, E.; Yanagi, K.; Moriguichi, K. Organometallics 1993, 12, 4188.

(19) Rankic, D. A.; Lucciola, D.; Keay, B. A. Tetrahedron Lett. 2010, 51, 5724.

(20) Obtained by reaction of $\mathbf{1 b}$ with norbornadiene using (S)-DMBINAP as the ligand followed by treatment with $\mathrm{HCl}$. 
(21) For a theoretical study of the asymmetric Heck reaction using P,Nligands see: Henriksen, S. T.; Norrby, P.-O.; Kaukoranta, P.; Andersson, P. G. J. Am. Chem. Soc. 2008, 130, 10414.

(22) For a similar result using a related $\left[\mathrm{Pd}^{0}(\mathrm{QUINAP}]\right.$ system see ref $14 \mathrm{~b}$.

(23) Legault, C. Y. CYLview, 1.0b; Université de Sherbrooke: Sherbrooke, Canada, 2009 (http://www.cylview.org).

(24) Remarkably, an erosion of the enantioselectivity of the major product is observed when the original system reported by Hayashi [Ref. 18, PhOTf / $(R)$-BINAP; $82 \%$ ee $(R)$ ] is modified with a bulkier ligand [ref 17 : PhOTf / (R)-DM-BINAP, 21\% ee $(R)$ ] or combination of bulkier ligand and substrate [this work, biphenyl triflate / (R)-DM-BINAP, 9\% ee $(S)$ ]. This observation puts in context the excellent results observed with heterobiaryl substrates. 
SYNOPSIS TOC (Word Style "SN_Synopsis_TOC").

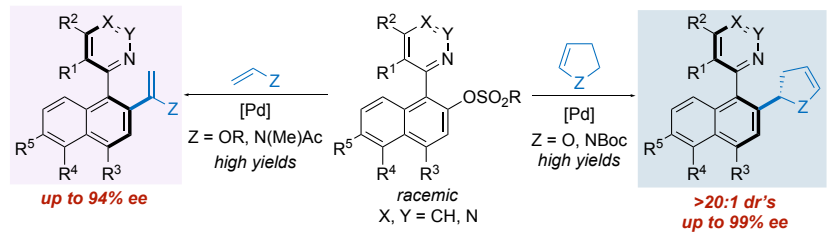

